\title{
CHEMOTAXONOMIC SIGNIFICANCE OF FLAVONOIDS IN THE SOLANUM NIGRUM COMPLEX
}

\author{
AYESHA MOHY-UD-DIN *, ZAHEER-UD-DIN KHAN, MUSHTAQ AHMAD, MUHAMMAD AKRAM KASHMIRI, \\ SAMMIA YASMIN, HINA MAZHAR
}

Centre for Plant Product Research, Department of Chemistry, GC University, Katchery Road, Lahore 54000, Pakistan.

(Received: April 14, 2009 - Accepted: August 24, 2009)

\begin{abstract}
Five locally available plant taxa of Solanum nigrum Complex were investigated to resolve the International taxonomic controversy about these plants by analyzing their flavonoid profiles. Total flavonoid contents in the taxa were determined by two complementary colorimetric methods, aluminum chloride method and 2,4-dinitrophenylhydrazine method. Thin layer chromatography was used to detect the glycosides of quercetin. Whereas GC-MS analysis of the hydrolyzed extracts showed the relative percentage of quercetin aglycon in the taxa under study. Statistical analyses of the results were employed for grouping of these taxa into various clusters. The significant distance found between $S$. americanum, S. chenopodioides, S. nigrum and S. villosum indicated them as distinct species. But S. retroflexum did not show such a marked difference and hence might be regarded as a variety or subspecies of S. nigrum.
\end{abstract}

Keywords: Solanum nigrum Complex, Flavonoids, Chemotaxonomy.

\section{INTRODUCTION}

Family Solanaceae comprises of about 84 genera and 3000 species $^{1}$ and Solanum is one of its most important and largest genera. Solanum nigrum is the largest and most variable species of the genus Solanum and is now named as Solanum nigrum Complex because it is composed of a large number (about 30) of morphologically distinct taxa ${ }^{2}$. Plants are not only a source of food and fodder showing high nutritional value ${ }^{3}$ but are medicinally important as well $1^{4,5}$.

There have always been debates concerning the taxonomic complexity of species associated with the section Solanum ${ }^{6,7}$. The species related to $S$. nigrum have shown variations and similarities in various morphological aspects. This has obscured the morphological limits of the species and caused taxonomic confusion. For this reason, the species have been re-classified many times but no satisfactory revision of the whole section has yet been devised. The boundaries between many of the species are still ill-defined, with many of the 'new' taxa proving to be no more than slight morphological variants of those already described. The situation has been further complicated by a number of authors, who have persistently treated different members of the section as belonging to one species, $S$. nigrum

Three taxa belonging to $S$. nigrum Complex viz.: S. americanum Mill., $S$. nigrum L. and S. villosum Mill. had been reported in Pakistan by Schilling and Andersen $^{2}$. S. chenopodioides Lam. and S. retroflexum Dunal are two other species that were found growing wild in and around the Botanical Garden, GC University, Lahore. On the basis of their morphological characters, classification of these taxa as being different varieties of $S$. nigrum or distinct species is controversial among the taxonomists. Morphological characters of these five taxa are compared in Table 2. Each of these taxa has its own specific medicinal and nutritional value ${ }^{8}$. Therefore, it is essential, for human health safety and quality control of the herbal medicine, to develop efficient methods for species identification/ delimitation. Their chemical analysis must be carried out to find out their relationship between them.

Flavonoids are widely occurring polyphenolic compounds and are extremely important because of their medicinal effects ${ }^{9}$. Flavonoids from different species of Solanum have been reported and reviewed ${ }^{10}$. Quercetin and its derivative glycosides make up most of the flavonoid content in $S$. nigrum $^{11}$. But the reports mostly did not take into account the morphological taxonomic complication associated with $S$. nigrum Complex and hence caused uncertainty. Flavonoids are useful secondary metabolites in assessing the relationship among closely related species or in studies of infraspecific variation, and they are also occasionally useful in assessing phylogenetic relationships at higher levels ${ }^{12-14}$. The epicuticular components ${ }^{15}$, various terpenoids, sterols and flavonoids have systematic significance and can be used for solving taxonomic problems ${ }^{16,17}$. GC-MS has been used in a number of occasions for the analysis of flavonoids in plant. For example, in one study ${ }^{18}$, it was used to characterize the flavonol aglycons in tomatoes (Solanum lycopersicum L.). In another study, the flavonoid aglycons isolated from Propolis were identified by GC$\mathrm{MS}^{19}$. Also GC-MS was claimed to be useful in chemosystematics helping, for example, to characterize species on the basis of their cuticular wax ${ }^{15,20}$. We could not find any report on the analysis of flavonoids of S. nigrum Complex by GC-MS and use of flavonoids in its chemotaxonomy. So to search out the boundaries between these five taxa using the chemotaxonomy to help resolve the International morphological taxonomic controversy on S. nigrum Complex we aimed to study their flavonoid profiles by comparing the total flavonoid contents, quantitative comparison of quercetin aglycon by GC-MS along with qualitative study of their glycosides using TLC.

\section{EXPERIMENTAL}

\section{Plant material}

Plant samples of five morphologically different plant taxa of Solanum nigrum Complex were grown under controlled conditions in Botanical Garden of GC University Lahore, Pakistan, each in specified area and third accession of each was taken (approx. $1 \mathrm{Kg}$ each) at flowering-seeding stage for chemotaxonomic investigation. Voucher specimens were authenticated and deposited in Dr. Sultan Ahmad Herbarium of GC University Lahore, Pakistan (Table 3).

\section{Chemicals and Standards}

Flavonoid standards Quercetin dihydrate and Naringin were purchased from MP. Biomedicals Inc. (Solon, Ohio). Methanol (HPLC grade), ethanol $(100 \%)$, ethyl acetate, $n$-butanol, acetic acid, aluminum chloride $\left(\mathrm{AlCl}_{3}\right)$, potassium acetate $\left(\mathrm{CH}_{3} \mathrm{COOK}\right), 2$,4-dinitrophenylhydrazine (DNPH), potassium hydroxide $(\mathrm{KOH})$, ammonia solution, hydrochloric acid $(\mathrm{HCl})$ and sodium hydrogen carbonate $\left(\mathrm{NaHCO}_{3}\right)$ were purchased from E-Merck (Darmstadt, Germany).

\section{Sample preparation for Colorimetric analysis}

Each of the plant samples was dewaxed by dipping in $n$-hexane for 45 $\mathrm{sec}^{21}$. Flavonoids were extracted for colorimetric analysis as described by Chang et $\mathrm{a}^{22}$. About $1 \mathrm{~g}$ (accurately weighed to $0.0001 \mathrm{~g}$ ) each of dewaxed powdered plant sample was extracted with $25 \mathrm{~mL}$ of $95 \%$ ethanol under 200 rpm shaking for $24 \mathrm{hr}$. After filtration, the filtrate was adjusted to $25 \mathrm{~mL}$ with $80 \%$ ethanol and stored in an amber bottle.

\section{Colorimetric analysis}

(I) Aluminum Chloride Colorimetric Method: The aluminum chloride colorimetric method was modified from the procedure reported by Woisky and Salatino ${ }^{23}$. Quercetin was used to make the calibration curve. Ten milligrams of quercetin was dissolved in $80 \%$ ethanol and then diluted to 25,50 and 100 $\mu \mathrm{g} / \mathrm{mL}$. The diluted standard solutions $(0.5 \mathrm{~mL})$ were separately mixed with $1.5 \mathrm{~mL}$ of $95 \%$ ethanol, $0.1 \mathrm{~mL}$ of $10 \% \mathrm{AlCl}_{3}, 0.1 \mathrm{~mL}$ of $1 \mathrm{M} \mathrm{CH}_{3} \mathrm{COOK}$ and $2.8 \mathrm{~mL}$ of distilled water. After incubation at room temperature for $30 \mathrm{~min}$, the absorbance of the reaction mixture was measured at $415 \mathrm{~nm}$ with a Shimadzu UV-1700 Pharma Spec. spectrophotometer. The amount of $10 \% \mathrm{AlCl}_{3}$ was substituted by the same amount of distilled water in a blank test. Then 0.5 $\mathrm{mL}$ of each ethanolic extracts with the $\mathrm{AlCl}_{3}$ solution for determination of flavonoid content as described above.

(II) 2,4-Dinitrophenylhydrazine Colorimetric Method: The current method was modified from the procedure described by Nagy and Grancai ${ }^{24}$. Naringin was used as the reference standard. Twenty milligrams of naringin 
was dissolved in methanol and then diluted to 500,1000 and $2000 \mu \mathrm{g} / \mathrm{mL}$. One milliliter of each of the diluted standard solutions was separately reacted with 2 $\mathrm{mL}$ of $1 \% 2,4-\mathrm{DNPH}$ reagent and $2 \mathrm{~mL}$ of methanol at $50^{\circ} \mathrm{C}$ for $50 \mathrm{~min}$. After cooling to room temperature, the reaction mixture was mixed with $5 \mathrm{~mL}$ of $1 \%$ $\mathrm{KOH}$ in $70 \%$ methanol and incubated at room temperature for $2 \mathrm{~min}$. Then, 1 $\mathrm{mL}$ of the mixture was taken, mixed with $5 \mathrm{~mL}$ of methanol and centrifuged at $1,000 \mathrm{x}$ g for $10 \mathrm{~min}$ to remove the precipitate. The supernatant was collected and adjusted to $25 \mathrm{~mL}$. The absorbance of the supernatant was measured at $495 \mathrm{~nm}$. The ethanolic extracts were similarly reacted with 2,4-DNPH for determination of flavonoid content as described above.

\section{Sample preparation for TLC and GC-MS analyses}

$30 \mathrm{~g}(10.0 \mathrm{~g}$ in a go $)$ of dewaxed plant material was extracted in a Soxhlet apparatus with methanol $(50 \mathrm{~mL})$. At 1 hour intervals, aliquots were removed and checked for the presence of flavonoids by TLC. After 5 hours, the extract showed absence of flavonoids. The extraction procedure was executed in triplicate. Each extract was then filtered and the volume was completed to $100 \mathrm{~mL}$ with methanol. $10 \mathrm{~mL}$ from this extract was filtered through a small column of C18 silica $(55-105 \mathrm{~mm}, 0.50 \mathrm{~g})$ and the column eluted with $8 \mathrm{~mL}$ of methanol. The volume of the eluate was completed to $20 \mathrm{~mL}$. More $5 \mathrm{~mL}$ of methanol was applied to the column and the eluate was checked for flavonoids, which were absent. Total volume of each extract was made $25 \mathrm{~mL}$.

TLC Procedure: Since quercetin, in its various glycosidic forms, has been the only flavonoid detected in S. nigrum Complex, the preliminary examination of the above extract by TLC was carried out according to the solvent systems recommended for quercetin glycosides ${ }^{25}$. Normal phase TLC was performed on precoated $(0.25 \mathrm{~mm})$ silica gel $60 \mathrm{~F}_{254}$ sheets (Merck, Darmstadt, Germany). The plates were developed separately in 1: BAW ( $n$-butanol-acetic acid-water, 4:1:5, top layer), $2: 15 \%$ Acetic acid $(\mathrm{AcOH})$ in water. The chromatograms were observed in UV light $(254 \mathrm{~nm})$ before and after exposing to ammonia vapors. Experiment was repeated thrice and the results are given in Table 1.

Acid Hydrolysis: The standard procedure used for the hydrolysis of quercetin glycosides in Solanum lycopersicum L. has been described by Hertog et $\mathrm{al}^{26}$. $\mathrm{HCl}(1.2 \mathrm{M}, 5 \mathrm{~mL})$ was added in the methanolic extract $(25 \mathrm{~mL})$ of each sample and the mixture was stirred at $90^{\circ} \mathrm{C}$ under reflux for 2 hours to obtain the aglycons by hydrolysis of flavonoid glycosides. The extracts were cooled to room temperature and extracted with ethyl acetate $(1: 1, v / v)$. Fractionation with $\mathrm{NaHCO}_{3}$ was performed according to the method described by Sabatier et $\mathrm{al}^{27}$. The ethyl acetate extract was treated with $0.5 \mathrm{~N} \mathrm{NaHCO}_{3}(1: 1, v / v)$ three times to eliminate the free phenolic acids. The ethyl acetate extract was evaporated to dryness under a flow of nitrogen and flavonols were re-dissolved in ethyl acetate. Each of the sample solution was filtered using $0.45 \mu$ polyamide filters (Sartorius, Germany) and was degassed by sonication for 3 min before injection. The filtrate $(1 \mu \mathrm{L})$ was injected into GC-MS

\section{GC-MS analysis}

GC-MS analysis was carried out using the conditions modified from the method of Tokusoglu et a $1^{18}$ used for the characterization of quercetin aglycon from hydrolyzed extract of Solanum lycopersicum L. GC-MS spectra were recorded on Shimadzu GCMS-QP2010A system in EI mode (70eV) equipped with a split/splitless injector $\left(280^{\circ} \mathrm{C}\right)$, at a split ratio of $50 / 50$ using DB-5MS column $(30 \mathrm{~m} \times 0.25 \mathrm{~mm}$ i.d., film thickness: $0.25 \mu \mathrm{m}$, J \& W Scientific, Fulsom, CA, USA). Helium was used as a carrier gas at the rate of $1 \mathrm{~mL} / \mathrm{min}$. 1 $\mu \mathrm{L}$ of sample was injected keeping ion source temperature $200^{\circ} \mathrm{C}$ and interface temperature at $250^{\circ} \mathrm{C}$. The column temperature was kept at $100^{\circ} \mathrm{C}$ for $1 \mathrm{~min}$ after injection and then increased at the rate of $10^{\circ} \mathrm{C} \mathrm{min}^{-1}$ to $275^{\circ} \mathrm{C}$ which was held for $20 \mathrm{~min}$. Standard stock solution $500 \mu \mathrm{g} / \mathrm{mL}$ of quercetin was prepared in methanol and the calibration curve was established using five dilutions of the standard solution in the concentration range of $0.1-2.0 \mu \mathrm{g} / \mathrm{mL} . \mathrm{R}^{2}$ value was 0.99 .

\section{Statistical analysis}

Experiments were performed in triplicate and the results were expressed as \pm Standard deviation (SD). Taxa under study were compared statistically on the basis of their flavonoid profile by Minitab 13 Statistical Software using Euclidean distances for similarity determination and Multivariate cluster procedure.

\section{RESULTS AND DISCUSSION}

\section{Species delimitation}

The difficulty of distinguishing genetically-controlled characteristics from phenotypic plasticity had long been known to impede species level taxonomy in Solanum ${ }^{9}$. The accessions of five morphologically different plant taxa of $S$. nigrum Complex were taken at flowering-seeding stage for chemotaxonomic investigation. All the accessions were homogeneous and did not suffer from any pest or disease. Morphological comparison of the taxa is given in Table 1.

Table 1. Morphological comparison of five taxa of Solanum nigrum Complex.

\begin{tabular}{|c|c|c|c|c|c|}
\hline Character & $S A^{a}$ & $S C$ & $S N$ & $S R$ & $S V$ \\
\hline Leaf shape & $\begin{array}{l}\text { Ovate-lanceolate to } \\
\text { lanceolate }\end{array}$ & Lanceolate & $\begin{array}{l}\text { Ovate-lanceolate, ovate- } \\
\text { rhombic }\end{array}$ & $\begin{array}{l}\text { Rhomboidal to ovate- } \\
\text { lanceolate }\end{array}$ & Rhombic to ovate-lanceolate \\
\hline Leaf margin & $\begin{array}{l}\text { Entire to sinuate rarely } \\
\text { sinuate-dentate }\end{array}$ & Entire to sinuate & $\begin{array}{c}\text { Sinuate or irregularly } \\
\text { dentate }\end{array}$ & Deeply lobed, 3-5(7) & Entire to sinuate-dentate \\
\hline Leaf length ${ }^{\mathrm{c}}$ & $2.5-3.2(4.0)$ & $2.7-5.4$ & $2.5-7$ & $4-4.8$ & $2.0-7.0(10)$ \\
\hline Leaf breadth & $1.1-4.0(4.6)$ & $(1.8) 2.2-5.4$ & $2.0-4.5$ & $3-4.2$ & $1.5-4.0(6.0)$ \\
\hline Inflorescence type & Umbellate cymes & Umbellate cymes & Extended cymes & $\begin{array}{l}\text { Simple to Umbellate } \\
\text { cymes }\end{array}$ & Umbellate to solitary cymes \\
\hline Corolla color & White, occasionally purple & White & White & $\begin{array}{l}\text { White with distinctive } \\
\text { purple stripes on each } \\
\text { petal }\end{array}$ & White \\
\hline Style length $^{\mathrm{d}}$ & $1.2-3.5(4.5)$ & $4.0-5.5(6.5)$ & $2.8-3.5(4.5)$ & $2-4.5$ & $2.9-5.0(6.0)$ \\
\hline Stylar exsertion & $\begin{array}{l}\text { Usually exserted beyond } \\
\text { anthers }\end{array}$ & $\begin{array}{l}\text { Exserted up to } 2 \mathrm{~mm} \\
\text { beyond anthers }\end{array}$ & $\begin{array}{l}\text { Not exserted beyond } \\
\text { anthers }\end{array}$ & $\begin{array}{l}\text { Exserted up to } 2 \mathrm{~mm} \\
\text { beyond anthers }\end{array}$ & Rarely exserted beyond anthers \\
\hline Cuticle & Shiny opaque & Dull opaque & Shinyopaque & Dull opaque & Translucent \\
\hline Seed length $^{\mathrm{d}}$ & $0.8-1.5$ & $1.0-1.8$ & $1.7-2.4$ & $1.5-2.3$ & $1.6-2.2$ \\
\hline
\end{tabular}

a Abbreviation of species, SA: S americanum, SC: S. chenopodioides, SN: S. nigrum, SR: S. retroflexum, SV: S. villosum.

${ }^{\mathrm{b}}$ Figures in parentheses refer to infrequent values below or above the regular range.

${ }^{c}$ Values are given in $\mathrm{cm}$

${ }^{\mathrm{d}}$ Values are given in $\mathrm{mm}$ 


\section{Colorimetric Analysis}

\section{(I) $\mathrm{AlCl}_{3}$ Colorimetric method}

Aluminium chloride forms acid stable complexes with the C-4 keto group and either the C-3 or C-5 hydroxyl group of flavones and flavonols. In addition it also forms acid labile complexes with the ortho-dihydroxyl groups in the A- or B-ring of flavonoids ${ }^{28}$. Complexes were prepared and scanned at different wavelengths. In ring A, Ortho-dihydroxyl groups showed maximum absorbance at 415-440 nm, C-4 keto group at $385 \mathrm{~nm}, \mathrm{C}-5$ hydroxyl group and Ortho-dihydroxyl groups in B ring at $415 \mathrm{~nm}$. In compromise, therefore, the wavelength $415 \mathrm{~nm}$ was chosen for absorbance measurement. However absorbance of complexes formed by flavanones such as naringin at this wavelength was too low to make the meaningful contribution to total absorbance. So these were estimated by 2,4-dinitrophenylhydrazine method. Quercetin is reported to be suitable for building the calibration curve $\mathrm{e}^{22,23}$. Therefore standard Quercetin solutions ranging from 50 to $150 \mu \mathrm{g} / \mathrm{ml}$ concentrations were used to build up the calibration curve. The coefficient of determination " $\mathrm{R}^{2}$ " was 0.953. Total amount of flavones, flavonols and isoflavones was calculated and tabulated (Table 2).

\section{(II) 2,4-dinitrophenylhydrazine for determination of flavanones}

The principle of this method is that 2,4-dinitrophenylhydrazine reacts with ketones and aldehydes to form 2,4-dinitrophenylhydrazones. It was found that flavones, flavonols and isoflavones with $\mathrm{C} 2-\mathrm{C} 3$ double bond could not react with 2,4-dinitrophenylhydrazine while the hydrazones of flavanones showed maximum absorbance at $495 \mathrm{~nm}$, and so this wavelength was selected for all measurements in the 2,4-dinitrophenylhydrazine reaction. Flavanone naringin, which was reported to show maximum absorbance at the above selected wavelength $^{22}$, was used to make the calibration curve. $\mathrm{R}^{2}$ value was 0.96 .

\section{Total flavonoid content}

Total flavonoid contents were represented as sum of two individual colorimetric methods. In fact, the total flavonoid contents determined by HPLC can be greatly influenced by the selected authentic standards and analytical conditions. Sometimes, limited by the availability of authentic standards, the identification of flavonoid peaks in chromatograms may be incomplete. Therefore to stay away from preconception, we conducted the quantitative determination of flavonoid contents in S. nigrum Complex by colorimetric analysis.

Results showed that flavonoid contents of five taxa as determined by aluminum chloride method, was much higher than those determined by $2,4-$ dinitrophenylhydrazine method (Table 2). The former ranged from $0.766 \pm$ $0.012 \%$ to $1.616 \pm 0.031 \%$ while the later ranged from $0.062 \pm 0.005 \%$ to $0.5 \pm$ $0.001 \%$. As suggested by Chang et $\mathrm{a}^{22}$, the flavones, flavonols and isoflavones formed complexes only with aluminum chloride, while flavanones strongly reacted only with 2,4-dinitrophenylhydrazine. So the contents determined by the two methods were added up to evaluate the total content of flavonoids. Results indicated that, among the five taxa investigated, $S$. chenopodioides contained the lowest level of total flavonoids $(0.883 \pm 0.020 \%)$, while $S$. nigrum showed highest level of total flavonoids $(2.116 \pm 0.032 \%)$ (Table 2). Overall, there was great variation in total flavonoid contents of the investigated taxa of S. nigrum Complex indicating that the quality of its medicinal use does require specification of the taxa taken.

Table 2. The flavonoid contents of five samples of S. nigrum Complex

\begin{tabular}{|l|c|c|c|}
\hline \multirow{2}{*}{ Sample } & \multicolumn{3}{|c|}{ Flavonoid content $\mathbf{( \% ) ^ { \mathbf { a } }}$} \\
\cline { 2 - 4 } & $\mathrm{AlCl}_{3}{ }^{\mathbf{b}}$ & $2,4-\mathrm{DNPH}^{\mathbf{c}}$ & Total \\
\hline S. americanum & $1.229 \pm 0.024$ & $0.438 \pm 0.010$ & $1.667 \pm 0.034$ \\
\hline S. chenopodioides & $0.821 \pm 0.015$ & $0.062 \pm 0.005$ & $0.883 \pm 0.020$ \\
\hline S. nigrum & $1.616 \pm 0.031$ & $0.500 \pm 0.001$ & $2.116 \pm 0.032$ \\
\hline S. retroflexum & $0.954 \pm 0.014$ & $0.250 \pm 0.001$ & $1.204 \pm 0.015$ \\
\hline S. villosum & $0.766 \pm 0.012$ & $0.125 \pm 0.002$ & $0.891 \pm 0.014$ \\
\hline
\end{tabular}

${ }^{\text {a }}$ Results were presented as mean $\pm \mathrm{SD}(\mathrm{n}=3)$.

${ }^{\mathrm{b}}$ Flavonoid content $(\%)=$ quercetin equivalent $(\mu \mathrm{g} / \mathrm{mL}) \times$ total volume of ethanol extract $(\mathrm{mL}) \div$ sample weight $(\mathrm{g}) \times 10^{-6}(\mathrm{~g} / \mu \mathrm{g}) \times 100$.

c Flavonoid content $(\%)=$ naringin equivalent $(\mu \mathrm{g} / \mathrm{mL}) \times$ total volume of ethanol extract $(\mathrm{mL}) \div$ sample weight $(\mathrm{g}) \times 10^{-6}(\mathrm{~g} / \mu \mathrm{g}) \times 100$.

\section{TLC Analysis}

TLC is a simple and reliable technique to compare the flavonoid profiles of different taxa and hence can be used to as an aid of their chemotaxonomy ${ }^{29}$. Various simple and complex glycosides of quercetin had been reported from $S$. nigrum Complex ${ }^{11,30}$. TLC of the extracts of the five taxa under study displayed variability in their flavonoid pattern (Table 3).

Table 3. TLC of methanolic extracts of five taxa of $S$. nigrum Complex.

\begin{tabular}{|c|c|c|c|}
\hline \multirow{2}{*}{$\begin{array}{c}\text { Plant Taxa } \\
\text { (Voucher No.) }\end{array}$} & \multirow{2}{*}{$\begin{array}{l}\text { No. of } \\
\text { spot }\end{array}$} & \multicolumn{2}{|c|}{$R_{f}$ value } \\
\hline & & BAW ${ }^{a}$ & $15 \%$ АсОН \\
\hline \multirow{3}{*}{$\frac{\text { Solanum americanum }}{\text { (G.C. Herb., Bot.-146) }}$} & 1 & 0.93 & 0.80 \\
\hline & 2 & 0.58 & 0.37 \\
\hline & 3 & 0.15 & 0.05 \\
\hline \multirow{5}{*}{$\frac{\text { Solanum chenopodioides }}{\text { (G.C. Herb., Bot.-243) }}$} & 1 & 0.93 & 0.90 \\
\hline & 2 & 0.83 & 0.62 \\
\hline & 3 & 0.58 & 0.37 \\
\hline & 4 & 0.36 & 0.12 \\
\hline & 5 & 0.13 & 0.02 \\
\hline \multirow{6}{*}{$\underset{\text { (G.C. Herb., Bot.-241) }}{\text { Solanum nigrum }}$} & 1 & 0.93 & 0.80 \\
\hline & 2 & 0.83 & 0.62 \\
\hline & 3 & 0.58 & 0.37 \\
\hline & 4 & 0.55 & 0.35 \\
\hline & 5 & 0.36 & 0.12 \\
\hline & 6 & 0.15 & 0.05 \\
\hline \multirow{5}{*}{$\frac{\text { Solanum retroflexum }}{\text { (G.C. Herb., Bot.-244) }}$} & 1 & 0.93 & 0.80 \\
\hline & 2 & 0.83 & 0.62 \\
\hline & 3 & 0.58 & 0.37 \\
\hline & 4 & 0.55 & 0.35 \\
\hline & 5 & 0.15 & 0.05 \\
\hline \multirow{4}{*}{$\frac{\text { Solanum villosum }}{\text { (G.C. Herb., Bot.-242) }}$} & 1 & 0.93 & 0.80 \\
\hline & 2 & 0.83 & 0.62 \\
\hline & 3 & 0.58 & 0.37 \\
\hline & 4 & 0.13 & 0.02 \\
\hline
\end{tabular}

${ }^{\text {a }}$ BAW: $n$-butanol-acetic acid-water, 4:1:5, top layer.

Two spots were identified on the basis of their $R_{f}$ values, color in UV light $(254 \mathrm{~nm})$ and UV light/ + ammonia ${ }^{25}$. Quercetin-3-glucoside (isoquercitrin) with $R_{f}$ values 0.58 (BAW) and 0.37 (15\% acetic acid) was detected in all the five taxa. But quercetin-3-galactoside having $R_{f}$ values 0.55 (BAW) and 0.35 (15\% acetic acid) was detected only in S. nigrum and $S$. retroflexum. Color of both spots was yellowish brown in UV light $(254 \mathrm{~nm})$ but turned to bright yellow when examined in the same light after treating with vapors of ammonia. Since these glycosides had been previously identified in different taxa of $S$. nigrum Complex ${ }^{11}$ and they are easy to detect by TLC, therefore, their presence in the samples can be indicated by comparing the observed properties with those reported in literature but other spots could not be characterized.

\section{Statistical analysis}

Characteristic occurrence of the flavonoid glycosides helped comparing the taxa statistically. S. nigrum and $S$. retroflexum resembled much closely and were first to segregate. This is because of presence of quercetin-3-galactoside in only these two taxa and much resemblance in their TLC pattern. However a spot $\left(\mathrm{R}_{\mathrm{f}}: 0.36\right)$ was missing in $S$. retroflexum which can be attributed to difference at sub-species level. This cluster was distantly related to $S$. americanum which showed relatively less number of spots. But $S$. villosum and S. chenopodioides formed another cluster having almost same similarity index as of the previously discussed cluster (Fig. 1). 


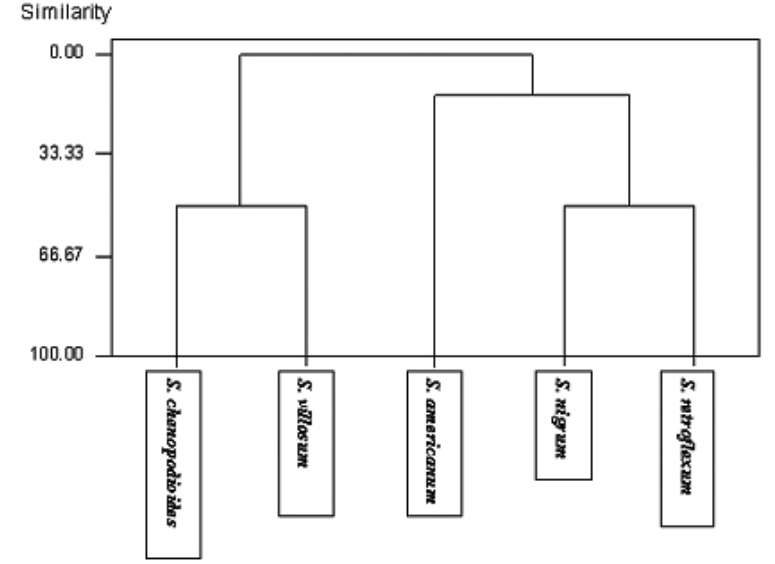

Fig. 1. Affinity relationships between different taxa of Solomum nigram Complex based on the distribution of components analyzed by TLC and determined by similarity and Multivariate cluster analysis.

\section{GC-MS analysis}

Quercetin in its different glycosidic forms has been the only flavonol reported from S. nigrum Complex ${ }^{11}$. The presence of quercetin aglycon in the hydrolyzed extracts of the five taxa under study was confirmed by GC-MS (Fig. 2).

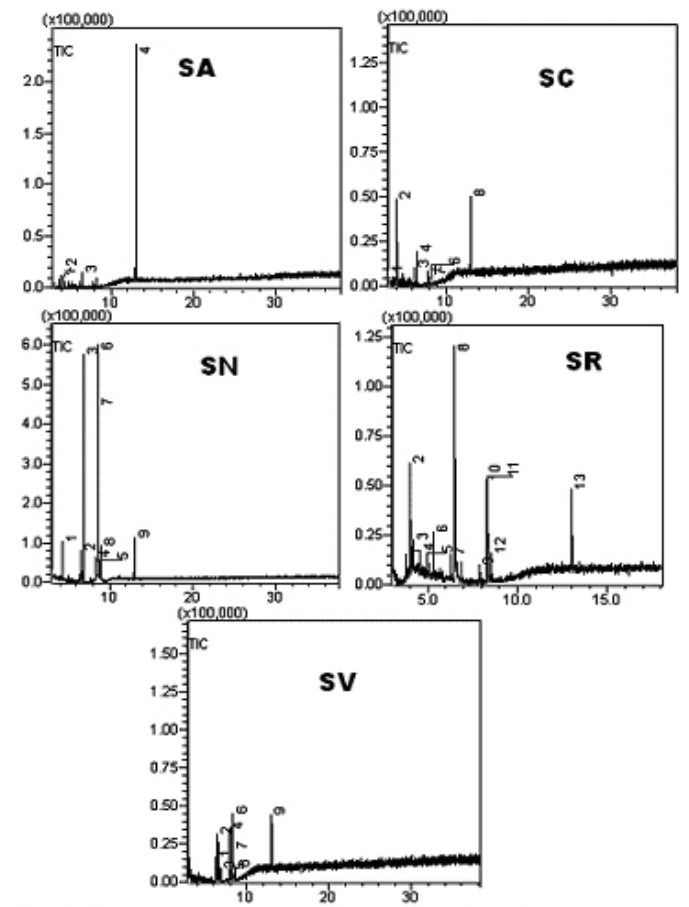

Fig. 2. Gas chromatograms of hydrolyzed extrads SA: S. comericonum, SC: S. chenopodioides, SN: S nigrum, SR: S. retroflexum, SV: S. villosum.

Retention time of quercetin standard was $13.012 \pm 0.001 \mathrm{~min}$. It showed molecular ion peak of $\mathrm{m} / \mathrm{z}$ (relative intensity in \%) at $304(22.8)$, base peak at 153 (100) with other characteristics peaks at 286 (4.0), 275 (27.6), 195 (2.8), 165 (12.4), 152 (24.4), 150 (21.2) and 123 (42.4). Quercetin in the samples was detected by spiking the samples with $0.5 \mu \mathrm{g} / \mathrm{mL}$ of standard quercetin solution and identified on the basis of comparison with the retention time and mass fragmentation pattern of the standard, and of the mass spectrum with the data from NIST 147 Library linked to the mass detector. The extreme variation in its percentage composition in the extracts from the taxa grown, harvested and analyzed under similar conditions decides its part in their chemotaxonomy
(Table 4). Comparing the area percentage, quercetin made up only $7.28 \%$ of the hydrolyzed flavonoid extract of $S$. nigrum and this continued to increase irregularly while moving to $S$. retroflexum, $S$. villosum and $S$. chenopodioides. But $S$.americanum stand alone in the group with such a high percentage (92.92\%). The calibration curve of standard was linear with $\mathrm{R}^{2}$ value of 0.99 in the concentration range of $0.1-2.0 \mu \mathrm{g} / \mathrm{mL}$. Amount of quercetin varied from $3.06 \pm 0.01$ to $6.46 \pm 0.01 \mathrm{mg} / 100 \mathrm{~g}$ of plant (Table 4). Yang et $\mathrm{al}^{31}$ reported the quercetin content of $S$. nigrum and $S$. villosum. Our results were in agreement with this study for $S$. nigrum $(3.7 \mathrm{mg} / 100 \mathrm{~g})$ but there was contradiction for $S$. villosum $(18.1 \mathrm{mg} / 100 \mathrm{~g})$. However, no reports could be found for quantitative studies of quercetin on other three taxa under study.

Table 4. Quercetin concentration in five taxa of S. nigrum Complex

\begin{tabular}{|c|c|c|c|}
\hline \multirow[b]{2}{*}{ Sample } & \multirow{2}{*}{$\begin{array}{l}\text { Retention time } \\
\text { (min) }\end{array}$} & \multicolumn{2}{|c|}{ Quercetin concentration ${ }^{a}$} \\
\hline & & $\begin{array}{l}\text { Percentage in } \\
\text { extract }^{\mathrm{b}}\end{array}$ & $\underset{\text { plant }^{\mathrm{c}}}{\mathrm{mg} / 100 \mathrm{~g} \text { of }}$ \\
\hline S.americanum & 13.019 & $92.92 \pm 0.45$ & $6.46 \pm 0.01$ \\
\hline S. chenopodioides & 13.008 & $38.31 \pm 0.23$ & $3.81 \pm 0.02$ \\
\hline S. nigrum & 13.011 & $7.28 \pm 0.33$ & $3.06 \pm 0.01$ \\
\hline S. retroflexum & 13.013 & $13.03 \pm 0.38$ & $3.18 \pm 0.01$ \\
\hline S. villosum & 13.012 & $23.94 \pm 0.28$ & $4.91 \pm 0.01$ \\
\hline
\end{tabular}

${ }^{a}$ Results were presented as mean $\pm \mathrm{SD}(\mathrm{n}=3)$.

${ }^{\mathrm{b}}$ Determined by area normalization method.

c Calculated from the calibration curve.

\section{Statistical analysis}

The percentage variation of the flavonoids observed in the five taxa by colorimetric and GC-MS analyses were used to group them statistically. Here again $S$. nigrum and $S$. retroflexum formed a closely related cluster with a high similarity index showing much similarity in their flavonoid profiles. $S$. chenopodioides and $S$. villosum, although not so closely related to one another as compared to the previously discussed cluster, made another cluster. $S$. americanum aligned more distantly with above mentioned clusters. This is due to its very high quercetin concentration (shown by GC-MS analysis) and very low flavanone percentage (in 2,4-dinitrophenylhydrazine method) as compared to other taxa (Fig. 3). This grouping pattern of these five was similar to that obtained while comparing their epicuticular wax composition ${ }^{32}$. Burbank ${ }^{33}$ claimed to have derived $S$. retroflexum plant by hybridizing $S$. guineense and $S$. villosum that raised a controversy. But Heiser ${ }^{34}$ had proved that it was not the claimed hybrid derivative but a distinct species native to South Africa and Burbank may have inadvertently introduced it into his experimental garden and subsequently selected it as a new plant. Their many morphological differences particularly corolla color, stylar exsertion and color and shape of berries (Table 1) and our results contradict with Burbank claim.

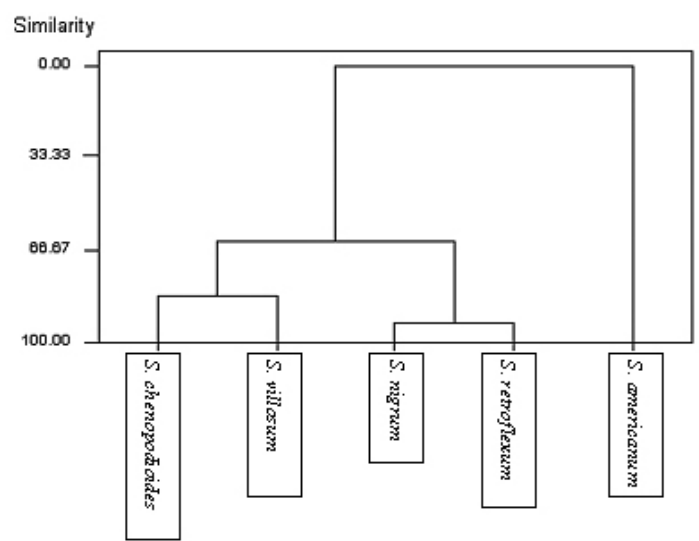

Fig. 3. Affinity relationships between different taxa of $S$. nigrum Complex based on their Flavonoid contents and Quercetin concentration, aralyzed by colorimetric methods and GC-MS and determined by similarity and Multivariate cluster aralysis. 


\section{CONCLUSIONS}

With various biological activities, flavonoids are the principal components in evaluating the quality as well as taxonomy of various taxa of $S$. nigrum Complex. The use of one colorimetric methods utilizing aluminum chloride reaction to determine flavonoid contents was proved to be specific only for flavones and flavonols, while another colorimetric method utilizing 2,4dinitrophenylhydrazine reaction was specific for flavanones. Therefore, we used both analyses so that the sum of the results may better represent the real content of total flavonoids. TLC was helpful in the preliminary examination of flavonoid glycosides. GC-MS analysis enabled the quantitative comparison of quercetin aglycon. The results suggested that $S$. americanum, S. chenopodioides, S. nigrum and S. villosum had significant differences and might be treated as separate species and not the varieties/ subspecies of $S$. nigrum. In case of $S$. retroflexum, many similarities with $S$. nigrum were observed. So it could be regarded as the variety/ subspecies of $S$. nigrum. Some minor differences could be attributed to differentiation at variety/ subspecies level. Moreover $S$. retroflexum had many morphological variations as compared to $S$. villosum and showed no relationship with later in this study thereby rejecting the Burbank's claim to be its hybrid. Because of the taxonomic misunderstanding surrounding the component species and the tendency to refer to all members as 'S. nigrum' it is advisable that the information found in literature should be reinterpreted and any medicinal/commercial use of the taxa should be carried out in the light of above chemotaxonomic suggestion.

\section{ACKNOWLEDGEMENTS}

We acknowledge Mr. Zafar Siddiq Department of Botany, GC University Lahore, Pakistan, for providing plant materials. We are grateful to Dr. Mohsin Iqbal Department of Biotechnology, GC University Lahore, Pakistan, for his help in statistical analysis. This work was partly financed by Higher Education Commission Pakistan.

\section{REFERENCES}

1. J. N. Yasin, Flora of Pakistan, vol.168. Pakistan Agricultural Research Council, Islamabad, 1985.

2. E. E. Schilling, R. N. Andersen, Bot. J. Linn. Soc. 102, 253, (1990).

3. V. N. Rzhavitin, Priroda 48, 107 (1959).

4. E. E. Schilling, Q. S. Ma, R. N. Anderson, Econ. Bot. 46, 223, (1992).

5. M. L. K. Manoko, R. G. van den Berg, R. M. C. Feron, G. M. van der Weerden, C. Mariai, Plant Syst. Evol. 267, 1, (2007).

6. G. L., Stebbins, E. F. Paddock, Madroño 10, 70, (1949).

7. D. E. Symon, Taxon 19, 909, (1970).

8. J. M. Edmonds, J. A. Chweya,. Black nightshades Solanum nigrum L. and related species, Institute of Plant Genetics and Crop Plant Research/ International Plant Genetic Resources Institute, Rome, 1997.
9. A. P.M. Bernardi, C. Lopez-Alarcon, A. Aspee, S. Rech, G. L. Von Poser, R. Bride, E. Lissp, J. Chil. Chem. Soc. 52, 1326, (2007).

10. T. M. S. da Silva, M. G. de Carvalho, R. Braz-Filho, M. de F. Agra, Quim. Nova 26, 517, (2003).

11. M. A. M. Nawwar, A. M. D. El-Mousallamy, H. H. Barakat, Phytochemistry 28, 1755, (1989).

12. E. C. Bate-Smith, Bot. J. Linn. Soc. 60, 325, (1968).

13. R. J. Gornall, B. A. Bohm, R. Dahlgren, Bot. Notiser 132, 1, (1979).

14. J. B. Harborne, B. L. Turner, Plant Chemosystematics, Academic Press, London, 1984.

15. A. Urzua, L. Mendoza, J. Chil. Chem Soc. 53, 1422, (2008).

16. M. R. M. Mimura, A. Salatino, M. L. F. Salatino, Biochem. Syst. Ecol. 32, 27, (2004).

17. G. S. Citoglu, B. S. Yilmaz, B. Tarikahya, R.Tipirdamaz, Chem. Nat. Compd. 41, 299, (2005)

18. O. Tokusoglu, M. K. Unal, Z. Yildirum, Acta Chromatogr. 13, (2003).

19. W. Maciejewicz, M. Caniewski, K. Bal, W. Markowski, Chromatographia 53, 343, (2001).

20. B. M. Szafranek, E. E. Synak, Phytochemistry 67, 80, (2006).

21. E. Medina, G. Aguiar, M. Gomez, J. Aranda, J. D. Medina, K. Winter, Biochem. Syst. Ecol. 34, 319, (2006).

22. C. Chang, M. Yang, H.Wen, J. Chern, J. Food Drug Anal. 10, 178, (2002).

23. R. Woisky, A. Salatino, J. Apicult. Res. 37, 99, (1998).

24. M. Nagy, D. Grancai, Pharmazie 51, 100, (1996).

25. J. B. Harborne, Phytochemical Methods, Chapman and Hall; London, 1974.

26. M. G. L. Hertog, P. C. H. Hollman, D. P. Venema, J. Agr. Food Chem. 40, 1591 (1992)

27. S. Sabatier, M. J. Amiot, M. Tacchini, S. Auberts, J. Food Sci. 57, 773, (1992).

28. T. J. Mabry, K. R. Markham, M. B. Thomas, The Systematic Identification of Flavonoids. Springer-Verlag. New York, U.S.A. 1970.

29. N. Kharazian, M. R. Rahiminejad, Int. J. Botany 4, 260, (2008).

30. E. E. Schilling, Biochem. Syst. Ecol. 12, 53, (1984).

31. R. Yang, S. Lin, G. Kuo, Asia Pac. J. Clin. Nutr. 17, 275, (2008).

32. A. Mohy-ud-din, Z. Khan, M. Ahmad, M. A. Kashmiri, S. Yasmin, M. N. Asghar, S. R. Ahmad, (accepted) Asian J. Chem. 21, (2009).

33. J. Whitson, R. John and H. S. Williams in Luther Burbank: His Methods and Discoveries and their Practical Application, L. Burbank, Luther Burbank Press; NY and London, 1914; pp. 105-133.

34. C. B. Heiser in Nightshades. The Paradoxical Plants, W. H. Freeman, San Francisco, 1969; pp. 62-105. 